\title{
Skin changes after bariatric surgery*
}

\author{
Ana Paula Dornelles da Silva Manzoni ${ }^{1}$
}

Magda Blessmann Weber ${ }^{1}$

\begin{abstract}
Today, obesity is considered an epidemic all over the world and it is recognized as one of the major public health problems. Bariatric surgery is considered an appropriate therapeutic option for obesity with progressively increasing demands. The changes resulting from massive weight loss after bariatric surgery are related to numerous complications. This article will present the dermatological alterations that can be found after bariatric surgery. They will be subdivided into dermatoses that are secondary to metabolic and nutritional disorders, those derived from cutaneous structural modifications after major weight loss and the influence the latter may have in improving of certain dermatoses.
\end{abstract}

Keywords: Bariatric surgery; Skin; Skin diseases

\section{INTRODUCTION}

Obesity is currently considered an epidemic that affects approximately 300 million people worldwide and is recognized as one of the major public health problems. ${ }^{1,2}$ Bariatric surgery (BS) is considered an appropriate therapeutic option for obesity with steadily increasing demands for it. ${ }^{3}$ Patients undergoing bariatric surgery experience significant improvement in medical co-morbidities, and also changes in patterns of hunger and satiety., Surgeries with the best outcomes can reduce body weight by up to $30 \%$ and $40 \%$ with results sustained for long periods. ${ }^{2,3}$

Changes resulting from extensive weight loss after bariatric surgery are linked to numerous complications that should be prevented and treated. ${ }^{3}$ In addition, new diseases are gradually being described, whilst physiopathogenic aspects resulting from the procedure and major weight loss are elucidated. ${ }^{2}$ From the dermatological point-of-view, reports are still sparse on this subject, but dermatologists should be prepared to understand the mechanisms by which bariatric surgery can cause cutaneous disorders and be attentive to diagnose and treat them.
The different techniques used to perform BS and the subsequent complications that may arise are discussed below to improve the understanding of their cutaneous effects.

\section{TYPES OF BARIATRIC SURGERY}

Bariatric surgeries are traditionally divided into three categories: restrictive procedures, malabsorptive procedures, and a combination of them.

Restrictive surgeries: include vertical banded gastroplasty with non-adjustable ring, laparoscopic adjustable gastric banding and sleeve gastrectomy. These techniques do not alter the qualitative or quantitative absorption of nutrients. ${ }^{4,5}$

Malabsorptive surgeries: include biliopancreatic diversion (BPD) and biliopancreatic diversion with duodenal switch (BPD/DS). These procedures cause malabsorption of both macro and micronutrients. ${ }^{4,5}$

Mixed procedures: Roux-en-Y gastric bypass (RYGB) surgery combines the procedures described above and induces changes in neurohormonal path-

Approved by the Advisory Board and accepted for publication on 10.10.2013

* Work performed at the Dermatology Service at Porto Alegre Federal University of Health Sciences (UFCSPA) - Porto Alegre (RS), Brazil.

Conflict of Interest: None.

1 Universidade Federal de Ciências da Saúde de Porto Alegre (UFCSPA) - Porto Alegre (RS), Brazil.

C2015 by Anais Brasileiros de Dermatologia 
ways that regulate energy balance. Malabsorption after RYGB is essentially limited to micronutrients and there is a lifelong need for vitamins and minerals supplementation to prevent deficiencies. Roux-en-Y complications are diverse and include distension of the remaining stomach, stoma stenosis, formation of marginal ulcers, cholelithiasis, ventral hernias, internal hernias, hypoglycemia, dumping, metabolic and nutritional disorders and weight regain., ${ }^{4,5}$

\section{GENERAL COMPLICATIONS OF BARIATRIC SURGERY}

Metabolic and nutritional diseases are among the main complications of bariatric surgery. ${ }^{4}$ These are secondary to decreased oral intake, as well as alterations in food absorption in the stomach and small intestine areas. ${ }^{5,6,7}$ Patients may also experience diarrhea, nausea and vomiting which may trigger fluid and electrolyte imbalance and that can persist for more than five years after surgery. $4,5.6$

The dietary approach after bariatric surgery is performed in stages, to ensure proper surgical wound healing and help developing good eating habits throughout life. ${ }^{2,8}$ However, when that does not occur, the body struggles to adapt and interpret its new physiological behavior, leading to secondary problems. Among those is the dumping syndrome, which occurs in approximately $50 \%$ of patients after RYGB. ${ }^{6,7}$ It is characterized by symptoms such as nausea, tremors, sweating, diarrhea, dizziness, flushing, tachycardia, and syncope resulting from the ingestion of food containing large quantities of refined sugars and also, from food eaten too quickly. ${ }^{7}$ Some authors consider this a positive effect after RYGB, particularly in patients who are partial to sweets, since it results in an aversion to the consumption of such foods. ${ }^{3,7,8}$

Another complication reported is the development of depression and sadness secondary to massive weight loss and the small amount of food that can be ingested due to the limited-size of the gastric pouch after surgery. ${ }^{5,9}$ The loss of food as an emotional support can result in illness and somatization. ${ }^{5}$

\section{DERMATOLOGICAL COMPLICATIONS OF BARIATRIC SURGERY}

Publications loss and its influence on the improvement of certain dermatoses.

\section{Metabolic and Nutritional Disorders}

Micronutrient and mineral nutritional deficiencies occur after bariatric surgery, especially after malabsorptive procedures. These disorders derive from inadequate food intake, changes in the digestive system's anatomy and high levels of oxidative stress that also interfere with the absorptive process. ${ }^{5,10}$ For exam- ple, in biliopancreatic diversion and biliopancreatic diversion with duodenal switch patients are at risk for protein malnutrition, so supplementation of 1.5 grams of protein per $\mathrm{kg}$ may be necessary. ${ }^{4,5,11}$ Micronutrient deficiencies are not commonly seen in gastric band procedures, however folate deficit has been described and should be regularly monitored, especially in women of childbearing age. Typically, patients undergoing RYGB show decreased absorption of liposoluble vitamins, iron, vitamin B12, A, D, E, K, folic acid and thiamine. ${ }^{11,12}$

Nutrients that may be lacking after bariatric surgery and that affect the skin are discussed below (Chart 1 and Table 1).

\section{VITAMIN A OR RETINOL}

Retinol is a liposoluble vitamin that is vital for retinal photoreceptors and the immune system functioning, as well as skin keratinization and the process of embryogenesis. ${ }^{13,14,15}$ It is usually found in foods derived from animal sources, such as cow's milk, liver, eggs and fish oils, besides $\beta$-carotene-containing vegetables or those with green and brightly-colored leaves, fruits like mango, damask, carrots and tomatoes. ${ }^{13,14,15}$

Vitamin A intake may be inadequate in patients with restrictive diets and eating disorders as can be seen after bariatric surgery. ${ }^{13}$ Vitamin A deficiencies can also be associated with fat malabsorption (necessary for this vitamin assimilation) as occurs after intestinal bypass surgery. ${ }^{13}$

Slater et al. observed decreased plasma levels of vitamin A in up to $69 \%$ of patients undergoing biliopancreatic diversion and clinical manifestations of this deficiency are present in as much as $10 \%$ of cases. ${ }^{16}$ Another factor commonly seen after BS, which may be involved in this hypovitaminosis, is the diminished absorption of protein, necessary for vitamin A assimilation. ${ }^{13,16}$

Xerophthalmia is the most important manifestation of vitamin A deficiency and it can cause blindness. ${ }^{15}$ Phrynoderma is the cutaneous finding classically associated with the lack of this vitamin (Chart 1 and Table 1). ${ }^{14,15}$ It is characterized by follicular and keratotic papules that usually affect the anterolateral surface of thighs and arms. Lesions may overtake the extensor surface of upper and lower limbs, shoulders, abdomen, dorsal area, buttocks and neck. It is important to note that, in the past, phrynoderma has been considered pathognomonic of vitamin A deficiency, but it probably represents a nonspecific finding common to cases of nutritional insufficiencies, as it was later associated to fatty acid, vitamin $\mathrm{E}$ and vitamin B2 deficiencies (Chart 1 and Table 1). ${ }^{13,14,15}$ Other cutaneous manifestations associated with vitamin A defi- 
CHART 1: Correlation of nutrient deficiency and its cutaneous repercussions

\begin{tabular}{|c|c|}
\hline NUTRIENT & CUTANEOUS REPERCUSSION \\
\hline Biotin & $\begin{array}{l}\text { Alopecia, glossitis, keratosis pilaris, periorificial dermatitis, seborrheic dermatitis and } \\
\text { erythroderma }\end{array}$ \\
\hline Copper & Depigmented and thinning hair, alopecia, delayed wound healing \\
\hline Iron & Pallor, koilonychia, glossitis, alopecia \\
\hline Selenium & Delayed wound healing, psoriasis, skin cancer \\
\hline Vitamin A or Retinol & $\begin{array}{l}\text { Xeroderma, acne, brittle hair, and keratotic follicular papules most commonly in the } \\
\text { anterolateral surface of thighs and arms, which may spread to the extensor areas of } \\
\text { the upper and lower limbs, shoulders, abdomen, dorsal region, buttocks and neck; } \\
\text { phrynoderma }\end{array}$ \\
\hline Vitamin B2 or Riboflavin & $\begin{array}{l}\text { Mucositis, lip and angular cheilitis, glossitis, xerosis, seborrheic dermatitis, scrotal } \\
\text { and vulvar eczema, erythroderma and toxic epidermal necrolysis. }\end{array}$ \\
\hline Vitamin B3 or Niacin & Pellagra, photosensitive dermatitis in symmetric areas, cheilitis, glossitis. \\
\hline Vitamin B5 or Pantothenic acid & $\begin{array}{l}\text { Purpura, leukotrichia, seborrheic dermatitis, angular stomatitis and glossitis. Burning } \\
\text { feet syndrome. }\end{array}$ \\
\hline Vitamin B6 or Pyridoxine & $\begin{array}{l}\text { Seborrheic dermatitis, glossitis, oral mucosa ulceration, lip and angular cheilitis, pho- } \\
\text { tosensitive pellagra-like lesions }\end{array}$ \\
\hline $\begin{array}{l}\text { Vitamin B9 or Folic acid and } \\
\text { B12 or Cobalamin }\end{array}$ & $\begin{array}{l}\text { Lip or angular cheilitis, Hunter's glossitis; diffuse, symmetric hair and mucocuta- } \\
\text { neous hypo-and hyperpigmentation }\end{array}$ \\
\hline Vitamin C or Ascorbic acid & $\begin{array}{l}\text { Poor wound healing, keratosis pilaris, perifollicular petechiae, ecchymosis, purpura, } \\
\text { brittle hair, scurvy (gingivitis, bleeding gums, keratosis pilaris), Sjögren-like syndrome }\end{array}$ \\
\hline Vitamin D & $\begin{array}{l}\text { Atopic dermatitis, psoriasis, skin infections, acne, autoimmune cutaneous diseases } \\
\text { and skin cancer. }\end{array}$ \\
\hline Vitamin E & Atopic dermatitis, acne. \\
\hline Vitamin $\mathrm{K}$ & Purpura, petechiae, ecchymosis, hematoma \\
\hline Zinc & $\begin{array}{l}\text { Acrodermatitis enteropathica (alopecia, acral and periorificial symmetric, erosive and } \\
\text { eczematous rash), dry, brittle and thinning hair, delayed wound healing, paronychia, } \\
\text { stomatitis, psoriasiform dermatitis, blepharitis, angular cheilitis, vitiligo-like lesions }\end{array}$ \\
\hline Protein & $\begin{array}{l}\text { Aged appearance, erythematous or hypopigmented lesions most evident in flexure } \\
\text { areas; hyperchromic lesions with smooth, fissured or erosive surface; brittle, slow } \\
\text { growing nails, onychomadesis; follicular hyperkeratosis, pale extremities accompa- } \\
\text { nied by edema; dry, brittle, dull, and thin hair, with brownish-red color before beco- } \\
\text { ming grayish-white, flag signal with alternating dark and light stripes in the hair; } \\
\text { angular cheilitis, xerophthalmia, stomatitis, vulvovaginitis }\end{array}$ \\
\hline
\end{tabular}

ciency are xeroderma, and thinning, brittle or corkscrew hair. The correlation between low plasma concentrations of vitamins $\mathrm{A}$ and $\mathrm{E}$ and the development of acne has been recently speculated. ${ }^{17}$

\section{VITAMIN B2 OR RIBOFLAVIN}

Riboflavin, in its biologically active forms, is an essential cofactor in the metabolism of numerous oxidative reactions..$^{15}$ It is also involved in the conversion of pyridoxine phosphate into vitamin B6. The 
TABLE 1: Correlation of nutrient deficiency and recommended treatment

\begin{tabular}{ll}
\hline NUTRIENT & SUPLEMENTATION/DAY IN CASE OF DEFICIENCY \\
\hline Biotin & Biotin $10 \mathrm{mg} /$ day p.o \\
Copper & Elemental copper 0.1 to $0.5 \mathrm{~g}$, intravenously, 2x/week \\
Iron & Ferrous sulphate, $500 \mathrm{mg} /$ day p.o \\
Selenium & Sodium selenite $200 \mathrm{mg} /$ day p.o \\
Vitamin A or Retinol & Vitamin A $50,000-200,000 \mathrm{IU} /$ day, p.o \\
Vitamin B2 or Riboflavin & Vitamin B2, 10 to $20 \mathrm{mg} /$ day, p.o \\
Vitamin B3 or Niacin & Nicotinic acid, $500 \mathrm{mg} /$ day, p.o \\
Vitamin B5 or Pantothenic acid & Pantothenic acid $10 \mathrm{~g} /$ day p.o \\
Vitamin B6 or Pyridoxine & Pyridoxine, $100 \mathrm{mg} /$ day p.o \\
Vitamin B9 or Folic acid and B12 or Cobalamin & Folic acid 1 to $20 \mathrm{mg} /$ day p.o \\
Vitamin C or Ascorbic acid & Vitamin C $500 \mathrm{mg}$ to $1 \mathrm{~g} /$ day p.o \\
Vitamin D & Vitamin D, 600 to $800 \mathrm{IU} / \mathrm{day}$ p.o \\
Vitamin E & Vitamin E, 400 to $800 \mathrm{mg} /$ day p.o \\
Vitamin K & Vitamin K, $1-3 \mathrm{mg} / \mathrm{single} \mathrm{dose} \mathrm{intramuscularly}$ \\
Zinc & Zinc, 15 to $30 \mathrm{mg} /$ day p.o \\
Protein & $1.5 \mathrm{~g}$ protein / kg p.o \\
\hline
\end{tabular}

main sources of riboflavin are milk and dairy products, fish, eggs, leafy greens and whole grains. The site of greatest absorption of this vitamin is the proximal small intestine. Deficiency may be caused by inadequate intake and intestinal malabsorption. . $1,18,19^{-19}$ Recently, cases of hypovitaminosis have been described after bariatric surgery with techniques that lead to macro and micronutrients malabsorption. ${ }^{18,20}$ Cutaneous manifestations associated with B2 deficiency are mucositis, angular and lip cheilitis, glossitis, xerosis, seborrheic dermatitis, scrotal and vulvar eczema, erythrodermia and toxic epidermal necrolysis. $15,18,19,20$ The severity of symptoms depends on the degree of riboflavin deficiency (Chart 1 and Table 1). ${ }^{15,20}$

\section{VITAMIN B3 OR NIACIN}

Vitamin B3 is converted into nicotinamide, which is an essential cofactor for human metabolism. It is easily found in meat, poultry, nuts, eggs, fish, coffee and beans. Intestinal bacteria convert nicotinamide in nicotinic acid that is transported to the liver, kidneys and intestines. ${ }^{15,19}$

Niacin deficiency is endemic in areas with low intake of meat, but may be associated with anorexia nervosa, alcoholism, food allergies, colitis, carcinoid syndrome, use of medications such as isoniazid, sulfonamides, anticonvulsants, antidepressants, azathioprine and chloramphenicol, and also, after gastrointestinal surgeries such as bariatric surgery. ${ }^{15,18,19,20}$

Pellagra is the dermatosis typically associated with niacin deficit, with a classic triad consisting on the presence of dementia, dermatitis and diarrhea. ${ }^{15,19}$ It is characterized by a symmetrical eruption resembling sunburn on sun-exposed areas. The dorsal areas of the hands are the most affected sites, which may present a glove-like distribution; the classic Casal necklace, and neck lesions are also seen. ${ }^{15,19}$ Other skin manifestations linked to niacin deficit are glossitis and angular and lip cheilitis (Chart 1 and Table 1). ${ }^{15,19}$

\section{VITAMIN B5 OR PANTOTHENIC ACID}

Coenzyme A $(\mathrm{CoA})$ is the biologically active form of pantothenic acid. ${ }^{21}$ It is an essential cofactor in many acetylation reactions. Its main food sources are egg yolk, liver, kidney, broccoli, chicken and beef, milk, potatoes and whole grains. ${ }^{15,21}$

CoA is hydrolyzed in the small intestine and absorbed in the jejunum. ${ }^{21}$ It plays a crucial role in the synthesis of vitamins A, D, cholesterol, steroids, hemoglobin, fatty acids, amino acids and proteins. Coenzyme A is also important in the cycles of several hormones. ${ }^{21}$

Vitamin B5 deficiency is related to the presence of purpuric lesions, leukotrichia, seborrheic dermatitis, angular stomatitis and glossitis. Another clinical manifestation is the "burning feet syndrome" marked by the presence of paresthesia and dysesthesia (Chart 1 and Table 1). ${ }^{15,19}$

\section{VITAMIN B6 OR PYRIDOXINE}

Vitamin B6 has three biologically active forms that are pyridoxine, pyridoxal and pyridoxamine. They are involved in the decarboxylation of amino acids, gluconeogenesis, conversion of tryptophane into niacin, sphingolipid biosynthesis, neurotransmitters synthesis, immunologic functions and modulation of steroid hormones. ${ }^{22}$ This vitamin is predominantly found in food sources like meat, whole grains and nuts. ${ }^{22}$ 
Vitamin B6 present in the food is phosphorylated by intestinal phosphatases and absorbed in the jejunum and ileum. Its deficiency is associated with inadequate diet (e.g. anorexia and alcoholism), malabsorption (e.g. bariatric surgery, Crohn's disease and celiac disease) and the use of drugs (e.g. isoniazid, hydralazine, contraceptives, penicillamine, theophylline). ${ }^{15,19,22}$

Characteristically, pyridoxine deficiency manifests itself through extensive seborrheic eczema. Glossitis, ulceration of the oral mucosa, lip and angular cheilitis may appear later. Severe cases may simulate pellagra and be accompanied by neurological symptoms such as drowsiness, confusion, and peripheral neuropathy. Hypochromic microcytic anemia may occur (Chart 1 and Table 1). ${ }^{15,19,22}$ There are reports on pyridoxine cytotoxicity induced by UVA radiation. ${ }^{23}$

\section{VITAMIN B9 OR FOLIC ACID AND VITAMIN B12 OR COBALAMIN}

Vitamins B9 and B12 are analyzed collectively, because their deficiencies lead to similar clinical manifestations. ${ }^{15,19}$ Lack of vitamin B12 is usually due to inadequate absorption of nutrients associated with pernicious anemia or gastric disorders. In contrast, deficiency of folic acid is generally attributable to inappropriate diet and/or alcoholism. Both insufficiencies can coexist in some patients with malabsorption, such as those undergoing surgical gastrectomy, with celiac disease or chronic diarrhea. ${ }^{8,11,12}$ Some medications, such as methotrexate, trimethoprim, oral contraceptives, pyrimethamine, anticonvulsants like phenobarbital and phenytoin also act as folic acid antagonists. ${ }^{12,19}$ Some articles herald vitamin B12 deficiency as the most commonly found after BS. This would occur due to decreased gastric acidity. ${ }^{24,25}$

Mucocutaneous manifestations secondary to these deficiencies include angular cheilitis, Hunter's glossitis (atrophy of the filiform papillae manifested by erythema and pain), hair depigmentation and also diffuse and symmetrical mucocutaneous hyperpigmentation more prominent on hands, nails, face, palm lines, folds and pressure points. Oral mucosa pigmentation can also be seen (Chart 1 and Table 1)..$^{15,19}$

The manifestations of folate and vitamin B12 deficits in other systems are: megaloblastic anemia and neurological manifestations, such as paresthesia, generalized weakness, symmetrical ataxia, spasticity, paraplegia, apathy, somnolence, irritability, memory loss, dementia, and psychosis. ${ }^{8}$ It is worth remembering that pernicious anemia related to vitamin B12 deficiency, may be associated with autoimmune diseases such as thyroiditis and vitiligo (Chart 1 and Table 1 ). ${ }^{26}$

\section{BIOTIN}

Biotin is an essential cofactor in the metabolism of amino acids. It is synthesized from ingested foods by intestinal bacteria; its main dietary sources being egg yolks, liver, nuts, peanuts, mushrooms, cow's milk and soy. ${ }^{27,28}$ This deficiency can be hereditary and rarely acquired. Prolonged total parenteral nutrition without addition of biotin, use of anticonvulsants (e.g., valproic acid, carbamazepine, phenytoin), factors that alter the intestinal flora (e.g., bariatric surgery) are among some of the causes of the acquired form. $15,27,28$

Alopecia, glossitis, keratosis pilaris, periorificial dermatitis, seborrheic dermatitis and erythroderma are dermatologic disorders associated with biotin deficiency. Systemic manifestations that may accompany them are conjunctivitis, vomiting, hypotonia, lethargy and metabolic acidosis (Chart 1 and Table 1)..$^{15,19,28}$

\section{VITAMIN C OR ASCORBIC ACID}

Vitamin C supports osteoblast formation in bones and teeth. It is an essential cofactor for the synthesis of carnitine, and catecholamines such as dopamine and norepinephrine. ${ }^{29,30}$ Ascorbic acid has an anti-oxidant action, stabilizes vitamin $\mathrm{E}$ and folic acid and also acts as a cofactor for the enzyme that catalyzes the formation of hydroxylysine and hydroxyproline. ${ }^{29,30,31}$ Flaws in this process interfere with collagen synthesis, which hinders skin healing, tooth formation, osteoblast and fibroblast production. Ascorbic acid is part of the metabolism of prostaglandins and prostacyclins, which when inadequately produced can generate decreased inflammatory response and increased immunological susceptibility. ${ }^{15,29,30}$

Vitamin C intake is dependent on the ingestion of citrus fruits, strawberries, tomatoes, vegetables and potatoes. ${ }^{31}$ It is absorbed in the upper third of the intestine and its deficiency is rare in developed countries. However, it can arise from improper diets as occur in situations of poverty, alcoholism, lack of access to fresh produce, anorexia nervosa, ulcerative colitis, Crohn's disease, Whipple's disease, kidney failure and bariatric surgery. ${ }^{31,32}$ It is worth noting that smoking decreases the intestinal absorption of vitamin C and increases its catabolism. ${ }^{33}$

Scurvy is the most severe expression of vitamin $\mathrm{C}$ deficiency. Its clinical manifestations tend to occur 1-3 months after the start of a deficient diet. The first signs are fatigue, malaise and lethargy. The first cutaneous disorder is keratosis pilaris on the lateral and posterior areas of the arms, buttocks and thighs. These lesions may become hemorrhagic particularly in areas of pressure. ${ }^{15,19}$ The main changes in the oral cavity are the presence of edematous, erythematous and friable gingivae with tendency to bleeding. Symptoms can 
mimic Sjögren's syndrome with xerosis and keratoconjunctivitis. ${ }^{15,19,29}$ Other findings include conjunctival and gastrointestinal bleedings, ungual linear hemorrhages reflecting the weakness of blood vessel walls, besides osteochondral changes and thinning hair in corkscrew (Chart 1 and Table 1). ${ }^{15,19}$ Anemia, secondary to blood loss, is a common finding in scurvy and it is usually associated with folate and iron deficiencies. $^{31}$

\section{IRON DEFICIENCY}

Iron is a vital mineral for cell homeostasis. It is essential for oxygen transportation, DNA synthesis and energy metabolism. It is an important cofactor for nitrogen fixation and mitochondrial respiratory chain enzymes. In mammals, it is mainly used in the synthesis of hemoglobin $(\mathrm{Hb})$ in erythrocytes, myoglobin in muscle cells and liver cytochromes. ${ }^{33,34}$ Iron absorption is carried out in the duodenal epithelium and some aspects, such as acidity and the presence of solubilizing agents like sugars, facilitate the intestinal absorption. ${ }^{34}$ One third of the iron acquired through diet is in the heme form, derived from the breakdown of hemoglobin and myoglobin contained in red meat. Eggs and dairy products provide smaller amounts of this form of iron, which is better absorbed than the inorganic form. ${ }^{34}$

Iron deficiency has consequences for the whole organism with anemia being the most relevant manifestation..$^{33}$ Dietary iron absorption is reduced after bariatric surgery, as a result of the smaller amount of gastric acids and the rapid transit through the main absorption sites. ${ }^{35,36}$ Iron deficiency is considered, by some publications, as the most common one after BS affecting up to $52 \%$ of patients. ${ }^{37,38}$ Prophylactic iron supplementation has been shown to effectively reduce the incidence of iron deficiency and the subsequent anemia. $37,38,39$

Secondary dermatologic manifestations to iron decrease described in the literature are pallor, glossitis and koilonychia (Chart 1 and Table 1). ${ }^{15,19}$

\section{COPPER DEFICIENCY}

Copper is one of the primary metals detected in the human body. It is found in the plasma, erythrocytes, cerebrospinal fluid, saliva and gastric secretions. Its absorption occurs through the ingestion of meat, seafood, some vegetables, grains and nuts. .0,41 $^{40}$

The main consequences of copper deficiency are neurological and hematopoietic disorders, but depigmented and brittle hair is also described. ${ }^{15,19}$ Pallor may be a clinical manifestation secondary to anemia (Chart 1 and Table 1). ${ }^{42,43}$ There are also reports that suggest that low serum copper levels can delay wound healing. ${ }^{15,19}$
Studies estimate that approximately $70 \%$ of women experience copper deficiency after BS. ${ }^{43,44}$ Publications also associate the reduced albumin absorption, often seen after bariatric surgery, as the cause of serum copper deficiency. ${ }^{25,45,46}$

\section{VITAMIN D DEFICIENCY}

Vitamin D synthesis starts in epidermal keratinocytes and dermal fibroblasts with the photoisomerization of 7-dehydrocholesterol (7-DHC or provitamin D3) to pre-vitamin D3. Eighty percent of this conversion occurs in the epidermis and requires ultraviolet light $\mathrm{B}$. It can also be obtained through dietary sources as ergocalciferol (vitamin D2) or be synthesized endogenously as cholecalciferol (vitamin D3). ${ }^{47,48}$ Fish oils have the highest quantity of available vitamin D, but egg, liver, shiitake mushrooms, and fortified products such as milk and orange juice are additional dietary sources. ${ }^{47,48}$

Fat malabsorption may predispose to vitamin $\mathrm{D}$ deficiency. The main causes are celiac disease, gastro surgical bypass, biliary atresia, cystic fibrosis, Crohn's disease, pancreatic and biliary illnesses. ${ }^{47,49}$ Hepatic and renal diseases, and the use of anticonvulsant drugs may also interfere with vitamin D metabolism. ${ }^{49}$

Slater $e t$ al. observed decreased plasma levels of vitamin D in up to $63 \%$ of patients submitted to biliopancreatic diversion with duodenal switch. ${ }^{16}$ This vitamin deficiency is asymptomatic in $65 \%$ of patients despite routine supplementation. About $71 \%$ of women have vitamin D deficiency after BS. ${ }^{25}$

Regarding the impact of vitamin D in dermatology, literature indicates that 1,25 dihydroxyvitamin D3 influences cell growth regulation and differentiation in keratinocytes and other cell types. Therefore, vitamin $\mathrm{D}$ analogues have been introduced for the treatment of psoriasis and other skin conditions. ${ }^{50}$ Vitamin D was recently identified in sebaceous cells, indicating that it may be effective in treating acne. ${ }^{51}$ Vitamin D also has activity on the immune system, thus influencing the protection against skin cancer and autoimmune diseases (Chart 1 and Table 1). ${ }^{52}$

Recently, literature has been emphasizing the impact of vitamin $\mathrm{D}$ in the pathogenesis of atopic dermatitis (AD) ${ }^{53}$ Considering the immunological mechanisms involved in $\mathrm{AD}$ pathogenesis, it is possible that vitamin D may influence it through immunomodulatory properties. It is known that the active form of vitamin $\mathrm{D}[1,25(\mathrm{OH}) 2 \mathrm{D} 3]$ increases the expression of antibacterial peptides preventing cutaneous infections. Some studies have demonstrated the link between vitamin D and Toll-like receptors, cathelicidin production and the increased susceptibility to bacterial infections. ${ }^{54,55}$ In addition, vitamin $\mathrm{D}$ stimulates the synthesis of proteins such as filaggrin, which 
is essential to the formation of stratum corneum. Thus, vitamin $\mathrm{D}$ deficiency may exacerbate $\mathrm{AD}$ by altering the skin barrier and undermining the immune system leading to subsequent increase in the risk of infections (Chart 1). ${ }^{53,55}$ Clinical observations investigate the relationship between disease exacerbation in winter and less exposure to solar radiation. Epidemiological studies have shown a higher prevalence of atopic dermatitis in countries with greater latitudes. ${ }^{54,55}$ The study by Lee found an inverse correlation between vitamin $\mathrm{D}$ serum concentrations and disease severity (Chart 1). ${ }^{56}$

Research has also been evaluating the role of vitamin D in hair growth regulation. Hydroxyvitamin D3 is the most active metabolite of vitamin D, and its primary function is calcium homeostasis regulation. Various tissues are involved in calcium metabolism, so the genetic inactivation of vitamin $\mathrm{D}$ receptor genes in mice resulted in hypocalcemia, secondary hyperparathyroidism, osteomalacia, rickets and alopecia. ${ }^{57}$

\section{VITAMIN E}

Vitamin E is widely found in various foods, especially vegetable oils. Vitamin E's active form is an antioxidant with stabilizing action against unsaturated lipids. It accumulates in cell membranes and lipoproteins. ${ }^{58,59,60}$ Membranes that protect lipoproteins and fatty acid from peroxidation reactions provide a high level of skin protection against ultraviolet radiation, and enhance the immune response. ${ }^{17,59}$

Studies report that low plasma concentrations of vitamins A and E may lead to the development of acne. ${ }^{17}$ Others emphasize the beneficial effects of vitamin $\mathrm{D}$ and $\mathrm{E}$ in the treatment of atopic dermatitis (Chart 1 and Table 1). ${ }^{59,60}$

\section{VITAMIN K}

Vitamin $\mathrm{K}$ is essential to the synthesis of several coagulation factors such as II, VII, IX, X, protein C and protein S. It is found in leafy greens, vegetables, liver, lentil, and soy and vegetable oils. Its absorption occurs via active transportation in the first third of the small intestine. Gastrointestinal bacteria synthesize approximately $50 \%$ of daily needs. ${ }^{61}$

Clinical deficiency of vitamin $\mathrm{K}$ may be secondary to low intake (e.g., anorexia, elderly patients, alcoholics), fat malabsorption (e.g., cystic fibrosis, biliary atresia, gastrointestinal surgeries as BS), use of antibiotics that alter the intestinal bacterial flora (e.g., cephalosporins, isoniazid, rifampicin) and vitamin Kinhibiting drugs (e.g., phenytoin, cholestyramine) ${ }^{61}$

Diminished plasma levels of vitamin K may occur in up to $69 \%$ of patients having biliopancreatic deviation with duodenal switch. Deficiency of this vitamin is asymptomatic in $65 \%$ of patients despite routine supplementation..$^{39}$ The main cutaneous manifestations secondary to vitamin $\mathrm{K}$ deficiency are related to the extravasation of blood into the skin as occurs in purpura, petechiae, ecchymoses, and bruising (Chart 1 and Table 1). ${ }^{15,19}$

\section{ZINC DEFICIENCY}

Zinc is a primordial element to the structural and regulatory functions of over 200 enzymes participating in biochemical pathways. ${ }^{62} \mathrm{It}$ is found in most products of animal origin, legumes, whole grains and dairy products, however, its absorption is limited. ${ }^{62,63}$

Zinc deficiency can be genetic or acquired. Whilst acrodermatitis enteropathica is its most important feature, the acquired form arises from low food intake, intestinal malabsorption (e.g., gastric bypass, inflammatory bowel disease, celiac disease, chronic diarrhea) or increased depletion (e.g., alcoholism, neoplasms, burns, infections, pregnancy, nephropathy and stress). ${ }^{62,63}$ Medications such as penicillamine, diuretics, antimetabolites, iron and valproate can lower serum zinc levels. ${ }^{62}$ The classic clinical triad of acrodermatitis enteropathica is comprised of diarrhea, alopecia and acral and periorificial rash. ${ }^{64}$ This rash tends to be symmetrical, eczematous and erosive. The hair can become dry, brittle and thin. Other cutaneous features caused by zinc deficiency are vitiligo-like lesions, delayed wound healing, paronychia, stomatitis, psoriasiform dermatitis, angular cheilitis and blepharitis (Chart 1 and Table 1). 15,19,63,64 There are also reports that low zinc serum levels may delay wound healing. ${ }^{65}$

The reduction in zinc serum levels after BS has been documented in the literature. ${ }^{66,67}$ The rates can be as high as $74 \%$ of women with zinc deficiency after bariatric surgery. ${ }^{25}$ It is believed that in cases of protein malnutrition secondary to surgery, there are changes in the intestinal structure and functions, with decrease of villi culminating in a reduced capacity of zinc absorption. Moreover, it is likely that the decline in gastric secretion and the oxidative stress resulting from surgery add to the metabolic demand, which also contribute to this diminished absorption. ${ }^{64}$

\section{SELENIUM}

Selenium's best-known function is that of an antioxidant, carried out by its association with glutathione peroxidase enzyme. Besides acting in the detoxification of hydrogen peroxide and other organic peroxides, glutathione peroxidase also maintains vital sulfhydryl groups in the reduced form, and it also acts on the synthesis of arachidonic acid-derived hormones and in the metabolism of extraneous compounds. ${ }^{68,69}$ Selenium can be found in rice, beans and flour. ${ }^{69}$ 
Selenium deficiency is already clearly related to increased risk of heart disease, immunodeficiency, male infertility and cancer. ${ }^{70}$ Alasfar et al found that morbidly obese women seeking BS as treatment had significantly reduced serum levels of selenium. ${ }^{71}$ Cutaneous repercussions of selenium deficiency are decreased wound healing, increased risk of psoriasis and skin cancer (both melanoma and non-melanoma types) (Chart 1 and Table 1).

\section{ENERGY-PROTEIN MALNUTRITION}

Energy-protein malnutrition (EPM) can be classified into marasmus, kwashiorkor and marasmuskwashiorkor. Marasmus refers to a global and chronic deficiency of nutrients due to lack of food intake or absorption. Kwashiorkor refers to a disproportionately greater absorption or ingestion of carbohydrates compared to fat and protein intake. Marasmus-kwashiorkor is an intermediate state between them. ${ }^{15,19}$ EPM is uncommon in adults, but it has been associated with anorexia nervosa and malabsorptive disorders like Crohn's disease, cystic fibrosis and post bariatric surgery. ${ }^{12}$ Kwashiorkor is the type of EPM most commonly seen in adults. ${ }^{74}$

A study shows that patients undergoing BS have about $6 \%$ albumin and $21 \%$ prealbumin deficiencies. ${ }^{25}$ From a dermatological point-of-view, the following manifestations can be found: dry, wrinkled skin giving a more aged appearance, erythematous or hypochromic lesions seen mostly in areas of friction or flexures, that over time become very evident, hyperpigmented, with smooth, fissured or erosive surfaces. Nails are brittle, slow growing and with areas of onychomadesis. Areas of follicular hyperkeratosis, pale extremities accompanied by swelling may also occur. ${ }^{15,19}$ The hair can be dry, brittle, dull, thin, with a red-brownish color before becoming grayish-white. The flag sign depicts alternate dark and light bands in the hair (Chart 1 and Table 1). 15,19,75 Angular cheilitis, xerophthalmia, stomatitis and vulvovaginitis may be seen as well. ${ }^{15,19}$

EPM treatment should be individualized according to the type and severity of presented manifestations. However, it is essential to correct their cause and supplement the deficient macronutrients. ${ }^{20}$

\section{PSORIASIS X BARIATRIC SURGERY}

Psoriasis is an inflammatory skin disease, for which obesity is considered a risk factor. Obese patients with psoriasis tend to have conditions that are more resistant to conventional treatments. ${ }^{76}$

Studies have suggested that gastric bypass surgery in patients with psoriasis can result in complete remission. The improvement starts immediately after surgery, before any weight loss. Medical literature postulates that it is secondary to increased levels of glucagon-like peptide-1 (GLP-1) produced by the intestine. Levels of GLP-1 may increase up to 20 times after gastric bypass surgery. This hormone is not hypersecreted after a purely restrictive gastric reduction, so treatment with gastric band does not lead to improvement of the disease. ${ }^{77,78}$

Although data on GLP-1 immunological actions are scarce in animal models or in vitro, there is a potential immunological effect that represents a link between bariatric surgery, GLP-1 and psoriasis. However, this hormone also acts directly on the skin as demonstrated in a study on the expression of GLP1 receptor in hair follicles of mice. ${ }^{76,77}$

\section{NECROBIOSIS LIPOIDICA $X$ BARIATRIC SURGERY}

Diabetes mellitus type 2 (DM2) is one of the most important comorbidities associated with obesity. The improvement of DM2 after bariatric surgery is a fact and therefore it has been publicized as "a metabolic surgery." The explanation for this is still unclear, since there is an assumption that it is not exclusively correlated with the weight loss. ${ }^{79}$

Necrobiosis lipoidica (NL), a dermatosis associated with diabetes, is characterized by single or multiple atrophic, erythematous-brownish, granulomatous lesions, which are located most often in the pretibial region; its precise etiology tough, remains unknown. Literature reported cases of NL remission after bariatric surgery. ${ }^{80}$ However, there is still much to be elucidated about the true mechanisms leading to this process. ${ }^{79}$

\section{POST-BARIATRIC SURGERY EXCESS SKIN}

After the massive weight loss following bariatric surgery, about $90 \%$ of patients tend to display the negative effects secondary to the large amount of redundant skin. ${ }^{5,81}$ In addition to the aesthetic problems, this leads to functional problems, dermatoses and difficulties in carrying on personal hygiene. ${ }^{10,81}$

The treatment of redundant skin is a necessary and essential step to improve the quality of life of patients after bariatric surgery. Nevertheless, there is clinical evidence on the differences in the healing and recovery processes of patients with massive weight loss after BS. ${ }^{81,82}$ Recent studies demonstrated that major weight loss is associated with damage in some components of the cutaneous extracellular matrix, particularly elastin fibers and collagen, which leads to higher rates of complications and poorer aesthetic results. ${ }^{82,83}$

After BS, the patient's skin presents lower concentrations of heparan sulfate, perlecan and increase 
in type III collagen. Heparan sulfates are attached to different proteins in the nucleus and they can be found on the cell surface and extracellular matrix, such as the basement membrane. They can interact with a wide range of proteins inducing biological activities such as cell proliferation, inflammation, hemostasis and angiogenesis, among others. Perlecan is a primary component of the basement membrane. ${ }^{82}$ It interacts with various growth factors such as vascular endothelial growth factor (VEGF)-A, which is essential for epidermal formation. ${ }^{81,83}$ Xing et al. also demonstrated, through an immunofluorescence study, the increased expression of type III collagen in the skin of patients after bariatric surgery. This is an immature collagen with less healing capacity. ${ }^{82}$ However, these studies were performed in vitro and further investigation on this topic is still necessary.

\section{REFERENCES}

1. Flegal KM, Carroll MD, Ogden $\mathrm{CL}$, Johnson $\mathrm{CL}$. Prevalence and trends in obesity among US adults, 1999-2000. JAMA. 2002;288:1723-7.

2. Santry HP, Gillen DL, Lauderdale DS. Trends in bariatric surgical procedures. JAMA 2005;294:1909-17

3. Buchwald H, Avidor Y, Braunwald E, Jensen MD, Pories W, Fahrbach K, et al. Bariatric surgery: a systematic review and meta-analysis. JAMA. 2004;292:1724-37.

4. Maglione MA, Gibbons MM, Livhits M, Ewing B, Hu J, Ruelaz Maher A, et al. Bariatric Surgery and Nonsurgical Therapy in Adults With Metabolic Conditions and a Body Mass Index of 30.0 to $34.9 \mathrm{~kg} / \mathrm{m} 2$. Rockville (MD): Agency for Healthcare Research and Quality (US); 2013.

5. Neff KJH, Roux CW. Bariatric Surgery. J Clin Pathol. 2013;66:90-8.

6. Santo MA, Pajecki D, Riccioppo D, Cleva R, Kawamoto F, Cecconello I. Early complications in bariatric surgery: incidence, diagnosis and treatment. Arq Gastroenterol. 2013;50:50-5

7. Hammer HF. Medical complications of bariatric surgery: focus on malabsorption and dumping syndrome. Dig Dis. 2012;30:182-6.

8. Fujioka K, DiBaise JK, Martindale RG. Nutrition and metabolic complication after bariatric surgery and their treatment. JPEN J Parenter Enteral Nutr. 2011;35:52S-9S

9. Sarwer DB, Dilks RJ, West-Smith L. Dietary intake and eating behavior after bariatric surgery: threats to weight loss maintenance and strategies for success. Surg Obes Relat Dis. 2011;7:644-51.

10. Hng KN, Ang YS. Overview of bariatric surgery for the physician. Clin Med. 2012;12:435-40.

11. Bordalo LA, Mourão DM, Bressan J. Nutritional deficiencies after bariatric surgery: why they happen? Acta Med Port. 2011;24:1021-8.

12. Mechanick JI, Youdim A, Jones DB, Garvey WT, Hurley DL, McMahon MM, et al. Clinical practice guidelines for the perioperative nutritional, metabolic, and nonsurgical support of the bariatric surgery patient--2013 update: cosponsored by American Association of Clinical Endocrinologists, The Obesity Society, and American Society for Metabolic \& Bariatric Surgery. Obesity (Silver Spring). 2013;21:S1-27.

13. Zalesin KC, Miller WM, Franklin B, Mudugal D, Rao Buragadda A, Boura J, et al. Vitamin A Deficiency after Gastric Bypass Surgery: An Underreported Postoperative Complication. J Obes. 2011;2011. pii: 760695.

14. Ocón Bretón J, Cabrejas Gómez MC, Altermir Trallero J. Frinoderma secundario a déficit de vitamina $A$ en un paciente con derivación biliopancreática. Nutr Hosp. 2011;26:421-4.

\section{DERMATOLOGICAL FOLLOW-UP POST-BS}

We suggest that the dermatologist watch out for the following points in patients submitted to bariatric surgery:

a. Anamnesis data: type of surgery performed (restrictive or not), current nutritional therapy, general symptoms (e.g., weakness, vomiting, diarrhea, neurological disorders, bleeding), history of recurrent cutaneous infections

b. Physical exam data: complete examination of the skin, mucosae and hairs.

c. Educate patients about personal hygiene cares on redundant skin.

d. Routinely prescribe moisturizers, since there are many deficiencies that can lead to xeroderma.

e. Beware of delayed healing in case of surgical procedures.

about cutaneous manifestations after to bariatric surgery are still sparse. At present, findings are restricted to changes due to metabolic and nutritional disorders, alterations in the skin structure after massive weight.
15. Jen M, Yan AC. Syndromes associated with nutritional deficiency and excess. Clin Dermatol. 2010;28:669-85.

16. Slater GH, Ren CJ, Siegel N, Williams T, Barr D, Wolfe B, et al. Serum fat-soluble vitamin deficiency and abnormal calcium metabolism after malabsorptive bariatric surgery. J Gastrointest Surg. 2004;8:48-55.

17. El-Akawi Z, Abdel-Latif N, Abdul-Razzak K. Does the plasma level of vitamins A and E affect acne condition? Clin Exp Dermatol. 2006;31:430-4.

18. Aasheim ET, Björkman S, Søvik TT, Engström M, Hanvold SE, Mala T, et al. Vitamin status after bariatric surgery: a randomized study of gastric bypass and duodenal switch. Am J Clin Nutr. 2009;90:15-22.

19. Palint JP. Physical Finding in Nutritional Deficiency. Ped Clin North Am. 1998:245-260

20. Koch TR, Finelli FC. Postoperative metabolic and nutritional complications of bariatric surgery. Gastroenterol Clin North Am. 2010;39:109-24.

21. Plesofsky-Vig N, Brambl R. Pantothenic acid and coenzyme A in cellular modification of proteins. Annu Rev Nutr. 1988;8:461-82.

22. Leklem, JE. Vitamin B6. In: Machlin LJ. Handbook of Vitamins. 2nd ed. New York: Marcel Dekker; 1991.

23. Maeda T, Taguchi H, Minami H, Sato K, Shiga T, Kosaka H, et al. Vitamin B6 phototoxicity induced by UVA radiation. Arch Dermatol Res. 2000;292:562-7.

24. Coupaye M, Puchaux K, Bogard C, Msika S, Jouet P, Clerici C, et al. Nutritional consequences of adjustable gastric banding and gastric bypass: a 1-year prospective study. Obes Surg. 2009;19:56-65

25. de Luis DA, Pacheco D, Izaola 0, Terroba MC, Cuellar L, Cabezas G. Micronutrient status in morbidly obese women before bariatric surgery. Surg Obes Relat Dis. 2013;9:323-7.

26. Sawicki J, Siddha S, Rosen C. Vitiligo and associated autoimmune disease: retrospective review of 300 patients. J Cutan Med Surg. 2012;16:261-6.

27. Mock, D. Biotin. In: Shils, M, Modern Nutrition in Health and Disease. 9th ed. Philadelphia: Lippincott Williams and Wilkins; 2000. p.459.

28. Lanska DJ. The discovery of niacin, biotin, and pantothenic acid. Ann Nutr Metab. 2012;61:246-53.

29. Lindblad M, Tveden-Nyborg P, Lykkesfeldt J. Regulation of Vitamin C Homeostasis during Deficiency. Nutrients. 2013;5:2860-79.

30. Mandl J, Szarka A, Bánhegyi G. Vitamin C: update on physiology and pharmacology. Br J Pharmacol. 2009;157:1097-110.

31. Jacob R. Vitamin C. In: Shils M, Olson J, Shike M, Ross AC, editors. Modern nutrition in health and disease. Philadelphia: Lippincott; 2000. p.467 
32. Riess KP, Farnen JP, Lambert PJ, Mathiason MA, Kothari SN. Ascorbic acid deficiency in bariatric surgical population. Surg Obes Relat Dis. 2009;5:81-6.

33. Cepeda-Lopez AC, Aeberli I, Zimmermann MB. Does obesity increase risk for iron deficiency? A review of the literature and the potential mechanisms. Int J Vitam Nutr Res. 2010;80:263-70

34. Theil EC. Iron homeostasis and nutritional iron deficiency. J Nutr. 2011;141:724S-728S.

35. Basfi-Fer K, Rojas P, Carrasco F, Valencia A, Inostroza J, Codoceo J, et al. Evolution of the intake and nutritional status of zinc, iron and copper in women undergoing bariatric surgery until the second year after surgery. Nutr Hosp. 2012;27:1527-35

36. Jáuregui-Lobera I. Iron deficiency and bariatric surgery. Nutrients. 2013;5:1595-608.

37. Brody F, Flood M, Richards NG, Vaziri K, Garey C, LeBrun C. A novel single agent for nutritional supplementation following Roux-en-Y gastric bypass. J Laparoendosc Adv Surg. 2013;23:596-600

38. Beckman L, Earthman C. Nutritional implications of bariatric surgery and the role of registered dietitians. J Acad Nutr Diet. 2013;113:398-9.

39. John S, Hoegerl C. Nutritional deficiencies after gastric bypass surgery. J Am Osteopath Assoc. 2009;109:601-4.

40. Danks DM. Copper deficiency in humans. Annu Rev Nutr. 1988:8:235-57.

41. Harvey LJ, Ashton K, Hooper L, Casgrain A, Fairweather-Tait SJ. Methods of assessment of copper status in humans: a systematic review. Am J Clin Nutr. 2009;89:2009S-2024S

42. Griffith DP, Liff DA, Ziegler TR, Esper GJ, Winton EF. Acquired copper deficiency: a potentially serious and preventable complication following gastric bypass surgery. Obesity (Silver Spring). 2009:17:827-31.

43. Prodan $\mathrm{Cl}$, Bottomley SS, Vincent AS. Copper deficiency after gastric surgery: a reason for caution. Am J Med Sci. 2009;337:256-8.

44. Griffith DP, Liff DA, Ziegler TR, Esper GJ, Winton EF. Acquired copper deficiency: a potentially serious and preventable complication following gastric bypass surgery. Obesity (Silver Spring). 2009;17:827-31.

45. Basfi-Fer K, Rojas P, Carrasco F, Valencia A, Inostroza J, Codoceo J, et al. Evolución de la ingesta y del estado nutricional de zinc, hierro y cobre en mujeres sometidas a cirugía bariátrica hasta el segundo año postoperatorio. Nutr Hosp. 2012:27:1527-35.

46. Chan CP, Wang BY, Cheng $\mathrm{CY}$, Lin CH, Hsieh MC, Tsou JJ, et al. Randomized controlled trials in bariatric surgery. Obes Surg. 2013;23:118-30.

47. Ben-Shoshan M. Vitamin D deficiency/insufficiency and challenges in developing global vitamin D fortification and supplementation policy in adults. Int J Vitam Nutr Res. 2012;82:237-59.

48. Battault S, Whiting SJ, Peltier SL, Sadrin S, Gerber G, Maixent JM. Vitamin D metabolism, functions and needs: from science to health claims. Eur J Nutr. 2013;52:429-41.

49. Cashman KD, Kiely M. Towards prevention of vitamin D deficiency and beyond: knowledge gaps and research needs in vitamin $\mathrm{D}$ nutrition and public health. $\mathrm{Br} \mathrm{J}$ Nutr. 2011;106:1617-27.

50. Stefanic M, Rucevic I, Barisic-Drusko V. Meta-analysis of vitamin D receptor polymorphisms and psoriasis risk. Int J Dermatol. 2013:52:705-10.

51. Reichrath J. Vitamin D and the skin: an ancient friend, revisited. Exp Dermatol. 2007;16:618-25.

52. Nürnberg B, Gräber S, Gärtner B, Geisel J, Pföhler C, Schadendorf D, et al. Progression of malignant melanoma is associated with reduced 25-hydroxyvitamin D serum levels. Anticancer Res. $2009 ; 29: 3669-74$.

53. Samochocki Z, Bogaczewicz J, Jeziorkowska R, Sysa-Jędrzejowska A, Glińska 0, Karczmarewicz E, et al. Vitamin D effects in atopic dermatitis. J Am Acad Dermatol. 2013;69:238-44.

54. Bergstrom KG. Evidence for supplement use in atopic dermatitis. J Drugs Dermatol. 2012;11:1245-7.

55. Roider E1, Ruzicka T, Schauber J. Vitamin D, the cutaneous barrier, antimicrobial peptides and allergies: is there a link? Allergy Asthma Immunol Res. 2013;5:119-28.

56. Lee SA, Hong S, Kim HJ, Lee SH, Yum HY. Correlation between serum vitamin D level and the severity of atopic dermatitis associated with food sensitization. Allergy Asthma Immunol Res. 2013;5:207-10.

57. Bollag WB. Mediator1: an important intermediary of vitamin D receptor-regulated epidermal function and hair follicle biology. J Invest Dermatol. 2012;132:1068-70.

58. Niki E, Traber MG. A history of vitamin E. Ann Nutr Metab. 2012:61:207-12

59. Dror DK, Allen LH. Vitamin E deficiency in developing countries. Food Nutr Bull. 2011;32:124-43

60. Javanbakht MH, Keshavarz SA, Djalali M, Siassi F, Eshraghian MR, Firooz A, et al. Randomized controlled trial using vitamins $E$ and $D$ supplementation in atopic dermatitis. J Dermatolog Treat. 2011;22:144-50.
61. Shearer MJ, Fu X, Booth SL. Vitamin K nutrition, metabolism, and requirements: current concepts and future research. Adv Nutr. 2012;3:182-95

62. Tuerk MJ, Fazel N. Zinc deficiency. Curr Opin Gastroenterol. 2009;25:136-43

63. Schwartz JR, Marsh RG, Draelos ZD. Zinc and skin health: overview of physiology and pharmacology. Dermatol Surg. 2005;31:837-47.

64. Cunha SF, Gonçalves GA, Marchini JS, Roselino AM. Acrodermatitis due to zinc deficiency after combined vertical gastroplasty with jejunoileal bypass: case report. Sao Paulo Med J. 2012;130:330-5.

65. Mirastschijski U, Martin A, Jorgensen LN, Sampson B, Ågren MS. Zinc, copper, and selenium tissue levels and their relation to subcutaneous abscess, minor surgery, and wound healing in humans. Biol Trace Elem Res. 2013;153:76-83.

66. Pires LV, Martins LM, Geloneze B, Tambascia MA, Hadad do Monte SJ, do Nascimento Nogueira N, et al. The effect of Roux-en-Y gastric bypass on zinc nutritional status. Obes Surg. 2007;17:617-21.

67. Cominetti C, Garrido AB Jr, Cozzolino SM. Zinc nutritional status of morbidly obese patients before and after Roux-en-Y gastric bypass: a preliminary report. Obes Surg. 2006;16:448-53.

68. Rayman MP. Selenium and human health. Lancet. 2012;379:1256-68.

69. Weeks BS, Hanna MS, Cooperstein D. Dietary selenium and selenoprotein function. Med Sci Monit. 2012;18:RA127-132.

70. Cassidy PB, Fain HD, Cassidy JP Jr, Tran SM, Moos PJ, Boucher KM, et al. Selenium for the prevention of cutaneous melanoma. Nutrients. 2013;5:725-49.

71. Alasfar F, Ben-Nakhi M, Khoursheed M, Kehinde EO, Alsaleh M. Selenium is significantly depleted among morbidly obese female patients seeking bariatric surgery. Obes Surg. 2011:21:1710-3.

72. Nazıroğlu M, Yıldız K, Tamtürk B, Erturan I, Flores-Arce M. Selenium and psoriasis. Biol Trace Elem Res. 2012;150:3-9.

73. Vinceti M, Dennert G, Crespi CM, Zwahlen M, Brinkman M, Zeegers MP, et al. Selenium for preventing cancer. Cochrane Database Syst Rev. 2014;3:CD005195.

74. Lewandowski H1, Breen TL, Huang EY. Kwashiorkor and an acrodermatitis enteropathica-like eruption after a distal gastric bypass surgical procedure. Endocr Pract. 2007:13:277-82

75. Rojas P, Gosch M, Basfi-fer K, Carrasco F, Codoceo J, Inostroza J, et al. Alopecia in women with severe and morbid obesity who undergo bariatric surgery. Nutr Hosp. 2011;26:856-62.

76. Halawi A, Abiad F, Abbas 0 . Bariatric surgery and its effects on the skin and skin diseases. Obes Surg. 2013;23:408-13.

77. Pérez-Pérez L, Allegue F, Caeiro JL, Zulaica JM. Severe psoriasis, morbid obesity and bariatric surgery. Clin Exp Dermatol. 2009;34:e421-2.

78. Bozkurt S, Coskun H, Kadioglu H, Memmi N, Cipe G, Ersoy YE, et al. Remission of Ulcerated Necrobiosis Lipoidica Diabeticorum after Bariatric Surgery. Case Rep Dermatol Med. 2013;2013:352579.

79. Dixon JB, le Roux CW, Rubino F, Zimmet P. Bariatric surgery for type 2 diabetes. Lancet. 2012 Jun 16;379:2300-11.

80. Buchwald H, Estok R, Fahrbach K, Banel D, Jensen MD, Pories WJ, et al. Weight and type 2 diabetes after bariatric surgery: systematic review and meta-analysis Am J Med. 2009;122:248-256.e5.

81. Aldaqal SM, Makhdoum AM, Turki AM, Awan BA, Samargandi OA, Jamjom H Post-bariatric surgery satisfaction and body-contouring consideration after massive weight loss. N Am J Med Sci. 2013;5:301-5.

82. Singh D, Forte AJ, Zahiri HR, Janes LE, Sabino J, Matthews JA, et al Prognostication for body contouring surgery after bariatric surgery. Eplasty. 2012:12:e46.

83. Mitchell JE, Crosby RD, Ertelt TW, Marino JM, Sarwer DB, Thompson JK, et al. The desire for body contouring surgery after bariatric surgery. Obes Surg. 2008:18:1308-12.
MAILING ADDRESS:
Ana Paula Dornelles da Silva Manzoni
Av. Carlos Gomes, 1998 conj. 405
Bairro Auxiliadora
90480-002 Porto Alegre, RS.
Email:anamanzoni@terra.com.br

How to cite this article: Manzoni APDS, Weber MB. Skin changes after bariatric surgery. An Bras Dermatol. 2015;90(2):157-68. 